\title{
How to play the role of network service in ideological and political education under the new situation
}

\author{
Ma Xueyu ${ }^{1, a}$, Zhang Hengze ${ }^{2, b}$ and Wang Lingxia ${ }^{3, c}$ Ding kun ${ }^{4, d}$ Li Ruiyu $^{5, e}$ \\ ${ }^{1}$ Department of Education Science Teaching of Xingtai University, 054001,China \\ ${ }^{2}$ Department of foreign languages of of Xingtai University, 054001,China \\ ${ }^{3}$ Department of Education Science Teaching of Xingtai University, 054001,China \\ ${ }^{4}$ Department of Education Science Teaching of Xingtai University, 054001,China \\ ${ }^{5}$ Second Affiliated Hospital of Xingtai Medical College 054000, China \\ email: Li Ruiyu651021@163.com
}

Keywords: Network services; The new situation; The ideological and political education

\begin{abstract}
With the rapid development of science and technology, the Internet has become a more and more important means and tool of communication in people's daily work and life in today's society. As a virtual space, network is so convenient, fast and flexible that it expands our knowledge and gives us infinite space to travel. But the Internet is a double-edged sword, which provides us convenience, at the same time brings many hidden trouble to our life. Therefore, while people are enjoying the convenience and shortcut network brings us, they also concern about network deeply. From the perspective of changing the cognition of the Internet, this paper puts forward reasonable suggestions and countermeasures to play the role of the Internet under the ideological and political education in the new times.
\end{abstract}

\section{Introduction}

Network is a virtual space, and its convenience, fastness, flexibility, and other advantages, expand our knowledge and give us infinite space to travel. It has changed our traditional way of life and made us browse books around the world even if staying at home. We also can get what aspect of information we want to know in the shortest time, and communicate with people on the other side of the globe face to face without leaving home. All these have made us feel the great convenience and quickness the network brings to our life. At the same time, we are constantly proving that our life and learning are inseparable from the network in practice.

Network is a double-edged sword, which provides us convenience, at the same time brings many hidden trouble to our life, such as "Internet addiction, Internet crime" and malignant events and influence like these. It is the network that makes it quickly spread to every corner of the world, not only interfering with our seeing and hearing, but also affecting our life, even leading to the formation of the shadow of network. The online dating, illegal websites and online games like candy-wrapped shells shoot to us. All kinds of illegal websites take advantage of the imperfect network management, and spread pornography and violence, which have had great impact on our physical and mental health.

Just because of this, people sink into worries about the Internet when enjoying the convenience brought by it. So how to deal with Internet correctly has become the problem which is deeply thought of by people, and it challenges the currently ideological and political education severely. The author thinks that there are some aspects concerning the functions of the Internet service towards the ideological and political education in new situation. 


\section{Change the distortedly either-black-or-white cognitive opinion towards the Internet}

From the technical point of view, the Internet is only a tool, it is neutral, if we don't use it, it will have not any influence on us. It is us who make ourselves drop into the dilemma of happiness and worry towards Internet, that is, our undue opinions and behavior style towards Internet cause our dilemma. From a psychological point of view, it is people's undue cognitive style causes people's false behaviors, in turn, the false behaviors deepen the undue cognitive style, if things go on like this, it will become a vicious circle. Therefore, people have to have a sober thought that Internet is just a tool which can improve our work efficiency and bring convenience to our life, but it can only be true when we use it correctly. Just like "The axe is the tool to cut firewood", if you take it to cut firewood, it is beneficial to your life. But if you beat your head with it, then it becomes a lethal weapon. So as long as we use Internet correctly and put it in an appropriate location in our mind, it will never be monsters but a technical tool that serves for us and improves our quality of life.

\section{Improve their own “Anti-virus capabilities”}

Because of the lack of antibodies to the virus, people will be affected by some virtues. And it is necessary to contact with the virus to produce the antibody. But as long as we expose to the virtue, we will possibly infect. Therefore, it is easy to go into the psychology approach-avoidance conflict[1]. The negative impact of network as a virtue exists objectively. Especially, this kind of virus is more harmful to teenagers, so some parents or teachers want to keep children from the Internet. They think if our children do not expose to the network, they will not be affected. Such as, don't contact with the computer and don't allow them to go to Internet bar strictly. In a word, as long as the children do not contact with the computer, they will not be addicted in the computer games. But conversely, the children will never produce the antibody to this network. Once we do not have the ability to isolate the children from the network, our children must be affected[1-3]. Thus, the right way is not to contact with the network, but we let them learn the ability and methods to cope with network, learning the choosing and distinguishing, to produce the ability to prevent the network virus, which is the fundamental way.

\section{Improve the Network Information Management Mechanism by Releasing Positive Information}

The worries about the network mainly derive from the "negative" information in the network, so in this era of transient information, our governments at all levels release information in time to make the public learn the truth of the matter, whether positive or negative. It will not spread various versions of truth to confuse people's eyes and ears, because of the natural curiosity, making the simple things more complex. So we should establish network supervision mechanism of information collection, processing ad rapid feedback as soon as possible. So as soon as possible we establish network supervision mechanism of information collection, processing and rapid feedback. Network supervision agencies at all levels should establish a set of effective screening, discrimination, research, processing and feedback information of the program. Arranging personnel to supervise the network information leads to summary and induction timely, collect carefully, discard the dross and select the essential, eliminate the false and retain the true. If verified by the processing, not only we must response quickly, accurately, timely and detailed information published on the Internet, but also inhibit the proliferation of false information. Through positive response, public truth and processing results timely to release the most real situation through the

${ }^{[1]}$ approach-avoidance conflict: : Approach-avoidance conflicts occur when there is one goal or event that has both positive and negative effects or characteristics that make the goal appealing and unappealing simultaneously. For example, People want to take advantage of the network of convenient and quick, but also worry about the harm done by the network. 
most authoritative channels so that let Internet users to comment more rational in the face of facts, maximize the positive effect of network, to offset the negative effect of the network ${ }^{[4]}$. Supervision authorities at various levels under the premise of performance according to law, response to the hot issues actively, introduce facts according to the facts, work honestly, rectify and reform modestly. Only in the first place can open all the content of the public in accordance with the law, take the initiative to explain to the public so that the public can trust the society, safeguard social fairness and justice and upset the ideological.

\section{Strengthen the network legislation, standard network "the market", developing the service function of the network extremely.}

Information is inextricably bound to human survival, so people cannot live without information, and everyday we deal with information, and use information for their own survival and development. Unconsciously, information mainly marked by interconnection network has influenced human life, study, office, shopping, travel, medical treatment, and entertainment profoundly. If going away, people can through the e-ticketing system to book tickets. The emergence of electronic shopping, network banking, securities, currencies, and various kinds of computer aided family financial management software, investment analysis software increasingly deepen people's life and become the good assistant of the people. Just a click on the keyboard in the home, you can avoid the trouble of crowding and queuing and save your precious time greatly.

However the anonymity of the network information makes it easier for people who are lack of discerning power to be deceived, while enjoying the convenience and speedy of the internet service. Therefore government department should take part in the usage and supervision of the internet and promulgate the law in legal supervision. Make clear the legality of internet supervision and regard it as the basic right of civil that should be protected seriously. Make further refining and defining about the internet supervision information to separate the illegal information from the legal one. What's more, government should regulate the behavior of supervision and punish those who spread vicious false information, frame others, endanger national security and suppress and take reprisals against internet supervision by administrative and legal means according to the seriousness of the circumstance and theirs harm to the society. Meanwhile, by using the positive and correct guidance of public opinion, government can help net citizen set up the correct internet morality which can reflect the problem objective and fairly and conduct supervision reasonable and lawful. And thus can achieve a harmonious situation in which all the people can use internet, benefit from it and supervise it $^{[5]}$.

In conclusion, nowadays, Internet has becoming more and more important space for survival in the society. However it is a virtual one. Unlike the real space which has strong defense against those who shouldn't enter in, the virtual defenseless one break up the dead line while make people come and go as they please. But if people could recognize and use internet correctly and draw on advantages and avoid disadvantages actively, they could improve their attainments, knowledge and realize their deserved value, and what's more turn internet into a good help in their daily life and study rather than fierce floods and savage beasts which endanger one’s life at any time.

\section{References}

[1] Zhu Quancheng, Bai Bing. The Countermeasures of Ideological and Political Education to the Juvenile Negative Behavior in Network Virtual Community[J]. Administration and law. 2011 (01)

[2] Liu Liu. Theory of Youth Ideological and Political Education Innovation under the Network Environment[J]. Heilongjiang Education Institute’s Journal. 2011 (04)

[3] Liu Man, Hu Yuan. Juvenile Challenges and Countermeasures of analysis of Ideological and Political Education under the Network Environment[J]. Hubei Education. 2011 (04) 
[4] Wen Daoqun. Juvenile Ideological and Political Education under the Network Background-— triggered by the "green dam” 2010(03)

[5] Hu Shuxiang, Xie Yujin. The network ideological and political education of the era of large data[J]. Studies in Ideological Education. 2013 (06) 